\title{
Responding to an in-flight medical emergency
}

Robin Chin Howe Low ${ }^{1}$, MMed, Dip AV Med, Choon How $\underline{H o w}^{2,3}$, MMed, FCFP

\begin{abstract}
Singapore's air travel bubble was finally in place and you were on board a four-hour flight to Hong Kong. As you settled back to watch a movie after the meal service, you heard an announcement: "We are seeking the assistance of a doctor or any healthcare provider. If you are one, please identify yourself to a member of our cabin crew." Even though you were unsure if you were sufficiently competent to attend to the medical condition, you bravely reached for the call button.
\end{abstract}

\section{WHAT IS AN IN-FLIGHT MEDICAL EMERGENCY?}

An in-flight medical emergency (IME) on commercial airlines is loosely defined as any clinical incident or condition involving any person on board that has likely exceeded the handling ability of the air crew, thus requiring further assistance.

\section{HOW RELEVANT IS THIS TO MY PRACTICE?}

Any doctor on a flight may be faced with a situation in which medical assistance is requested, as commercial air passenger numbers have been increasing year-on-year since 2004, when airlines flew two billion passengers. In 2019, commercial airlines carried a total of 4.5 billion passengers, and if not for the COVID-19 pandemic, this number would have increased to 4.7 billion in 2021.(1) The higher chances of encountering IMEs are attributed to a combination of factors, such as larger aircrafts (e.g. the Airbus A380) carrying more passengers and the introduction of low-cost carriers making flying accessible to more people, including older individuals and those with pre-existing medical conditions.

Although the cabin crew is trained to manage many minor complaints, such as a mild fever, giddiness or even minor trauma, an IME can be viewed as one that requires expertise beyond that of the cabin crew, in which case an announcement is made to seek a medical volunteer. Based on this definition, it is estimated that IMEs take place in approximately one of 604 flights. ${ }^{(2)}$ Other estimates range from 24 to 130 IMEs per one million passengers, which extrapolates to 260-1,420 IMEs daily (based on four billion passengers annually). ${ }^{(3)} \mathrm{A}$ review showed that such occurrences were assisted by medical doctors (48\% of cases), nurses $(20 \%)$, emergency medical service providers $(4.4 \%)$ and other healthcare professionals $(3.7 \%) .^{(2)}$

\section{WHAT ARE SOME CHARACTERISTICS OF THE AIRCRAFT CABIN?}

The aircraft cabin environment is different from the environment in which physicians see patients in our clinics. Aircraft cabins are pressurised tubes designed to transport passengers in a comfortable, liveable environment. Some passengers on long commercial flights have complained of symptoms similar to acute mountain sickness, ${ }^{(4)}$ as the cabin is pressurised to an altitude of 6,000-8,000 feet (e.g. the peak of Gunung Tahan, Malaysia, 7,175 feet) and not to sea level (e.g. Singapore). This translates to an atmospheric pressure of $609 \mathrm{mmHg}$ at 6,000 feet and 564 $\mathrm{mmHg}$ at 8,000 feet, compared to $760 \mathrm{mmHg}$ at sea level.

\section{Hypoxia}

The most significant effect of the higher altitude is the lower partial pressure of oxygen in the cabin environment (inspired partial pressure of oxygen: $108 \mathrm{mmHg}$ at 8,000 feet vs. $148 \mathrm{mmHg}$ at sea level), which is equivalent to breathing $15.1 \%$ oxygen at sea level. This results in hypobaric hypoxia, with most healthy passengers having a lowered oxygen saturation of $90 \%-93 \% .{ }^{(5)}$ While healthy adults do not have difficulty compensating for this mild hypoxia, passengers with already compromised cardiorespiratory function may decompensate and turn symptomatic.

\section{Gas expansion}

Another effect of the increased cabin altitude is the expansion of gases in any air-containing space in the body. Boyle's law states that at constant temperature, the volume of gas in an enclosed space varies inversely with pressure. At an altitude of 8,000 feet (564 mmHg atmospheric pressure), the volume of gas expands by approximately $30 \%-35 \% .{ }^{(3)}$ Some parts of the body that contain closed air spaces are the sinuses, middle ear, bowels and teeth (dental cavities or abscesses). Gas expansion in these spaces can result in barotrauma, with symptoms varying from mild discomfort to severe incapacitation.

Additionally, expanding air in unusual spaces such as postsurgical wounds (e.g. after abdominal or intracranial surgery), pulmonary bullae or even undiagnosed pneumothoraxes can result in unpleasant outcomes such as wound dehiscence, raised intracranial pressure or respiratory distress. There have been case reports of airline passengers with pulmonary disease who collapsed after experiencing breathing difficulty shortly after

${ }^{1}$ Aviation and Occupational Medicine, Singapore Aeromedical Centre, ${ }^{2}$ Care and Health Integration, Changi General Hospital, ${ }^{3}$ Family Medicine Academic Clinical Programme, SingHealth Duke-NUS Academic Medical Centre, Singapore

Correspondence: Dr Robin Low Chin Howe, Medical Director, Singapore Aeromedical Centre, 492 Airport Road, Singapore 539945. robinlow14@gmail.com 
take-off, and the subsequent autopsy indicated that they had developed tension pneumothorax, most likely from a ruptured bulla. ${ }^{(6)}$ Air in medical devices such as the cuffs of tubes and pneumatic splints can also be affected. ${ }^{(7)}$

\section{Cabin air quality}

The aircraft cabin is fed by air from the external environment, which is extremely dry at a flight altitude of 30,000-40,000 feet. As a result, the relative humidity of cabin air varies from $0 \%$ to $10 \%$. This dry air can result in dehydration, mucosal irritation of the nasal passages or dryness of the cornea, and exacerbation of diseases such as asthma. The cabins of the newest aircraft, such as the Boeing 787 and the Airbus A350, are pressurised to a lower altitude of 6,000 feet, with up to $15 \%-20 \%$ relative humidity, which has reportedly led to improvements in passenger comfort. Cabin air is also recirculated, with half being filtered through a high-efficiency particulate air filter and the other half drawn fresh from the exterior environment. Together with the cabin air refresh rate of 20-30 times per minute, the International Air Transport Association (IATA) maintains that the risk of transmission of infectious disease within the cabin environment is low. ${ }^{(8)}$

\section{Decompression sickness}

Generally, passengers flying on a commercial aircraft are not at risk of suffering from decompression sickness. However, passengers who have been scuba diving within 24 hours of the flight are at increased risk of developing decompression sickness due to the increased amount of nitrogen dissolved in their body fluids and blood plasma under high barometric pressure during diving. ${ }^{(7)}$ In the reduced atmospheric pressure of the cabin environment, the nitrogen precipitates as gas bubbles out of the solution and has the potential to obstruct blood flow to various organs, resulting in symptoms such as joint pain ('bends'), itching or mottling of the skin ('creeps'), or more rarely, severe symptoms such as breathlessness ('chokes'), stroke or even collapse. The Federal Aviation Administration (FAA) Civil Aerospace Medical Institute recommends that divers wait at least 24 hours between scuba diving and flying. ${ }^{(9)}$

\section{Other conditions}

Other common medical conditions that can occur on board an aircraft include motion sickness, which can be exacerbated by the anxiety of flying and/or unexpected turbulence. Abdominal discomfort can also occur from intestinal gas expansion due to the elevated cabin altitude. This can result in gastrointestinal upset, which can sometimes be severe enough to cause syncopal episodes.

\section{WHAT CAN I DO IN MY PRACTICE? Potential medical conditions}

With no standardised definition of IMEs, a responding medical professional can face a wide spectrum of illnesses ranging from syncope to actual death. Previous studies indicate that the most common medical condition resulting in an IME is syncope (33\%), followed by gastrointestinal symptoms (15\%) and respiratory symptoms $(10 \%)$. Other conditions include cardiovascular conditions ( $7 \%$ ), neurological conditions (5\%) and trauma (5\%). Obstetric or gynaecological symptoms make up only $0.5 \%$ of IMEs. ${ }^{(2,3)}$ While the responding doctor should be mentally prepared to encounter a serious condition, many IMEs can be managed with simple measures, including displaying compassion and reassurance.

\section{The cramped 'clinic' space}

Space is at a premium in aircraft cabins. This could pose a challenge when assessing the ill patient on board, or during attempts to perform cardiopulmonary resuscitation or procedures such as setting an intravenous line. If necessary, the patient can be shifted to a location with more space such as the galley, the space near the emergency exits or even in the aisle. In some situations, the patient may be taken to the business class section, but the cabin crew may be hesitant about causing disturbance to the premium passengers. Other factors that can complicate assessment of an ill patient are the constant noise, which renders the stethoscope almost useless, and the constant movement including air turbulence that makes it difficult to perform procedures. Finally, safety considerations require that the patient be strapped in during turbulence and for the landing phase. This may require moving the patient back to a seat, potentially complicating efforts to monitor the patient if they are unstable.

Regardless of the condition, it is anticipated that the responding doctor will be faced with a novel situation in an unfamiliar public environment that is unconducive to patient care, with many curious bystanders looking on. Hence, responding doctors need to maintain their composure and conduct an assessment using the basics of history-taking and physical examination. Box 1 shows the AMPLE (allergies, medication, past history, last meal and events leading to presentation) guide to taking a complete history.

\section{Equipment available on board}

All passenger-carrying aircrafts are required by the International Civil Aviation Organization (ICAO) to carry a first-aid kit for use by the cabin crew. A medical kit for medical doctors or other qualified persons is required on aircrafts carrying more than 100 passengers. In addition, the ICAO also mandates the carriage of a universal precaution kit for managing suspected cases of communicable diseases. ${ }^{(10)}$ However, these requirements are considered 'guidance', and the ICAO did not specify the quantity and contents of such kits. Therefore, national regulatory bodies and/or individual airlines are free to determine these aspects of these kits.

International professional bodies such as the Aerospace Medical Association (AsMA), the International Academy of Aviation and Space Medicine (IAASM) and IATA have mutually coordinated and agreed upon a set of recommendations for contents of first-aid, medical and universal precautions kits. This was most recently reviewed by the AsMA Air Transport Medicine Committee in 2019 together with the American Academy of Pediatrics, and agreed on by the Chief of the ICAO 
Box 1. AMPLE history and possible relevance to in-flight medical emergencies (IMEs):

\section{- Allergies: Any drug allergies?}

To be asked before administering any medication from the medical kit. The person may also be allergic to certain foods that he/she may have unknowingly consumed on board, triggering the IME. - Medication: Any medication taken - routine or otherwise. Passengers may take antihistamines or sedatives to sleep on board, which may alter presentation of consciousness. Routine medications may include antihypertensive and diabetic medications such as insulin. The changes in time zones during a flight may result in these medications being taken at the incorrect times. Other possible medications include psychiatric medications such as anxiolytics. These could also result in an IME.

- Past medical history: It is important to determine if the passenger has any premorbid condition, which may have precipitated the IME. Obvious conditions such as cardiovascular or respiratory diseases could result in a compromised cardiorespiratory status that is tipped into decompensation by the cabin environment. Past history also includes any recent history of surgery and/or trauma, especially chest or head trauma that may result in an undiagnosed pneumothorax or air in the intracranial cavity if the skull is fractured. Gas expansion from such events can result in a significant medical event.

- Last meal or drink: Less relevant in this setting.

- Events leading to presentation: This information can be obtained from anyone accompanying the affected passenger, or even from surrounding passengers or the cabin crew. It is important to ascertain the person's behaviour prior to the event. For example, hypoxia can lead to altered behaviour and emotions before triggering the IME.

Aviation Medicine Section, IATA and IAASM. The latest review recommended including kit contents that can support in-flight paediatric medical events. The recommended contents of the various kits are listed in Table I. ${ }^{(11)}$

Most airlines are equipped with the necessary items to comply with specific regulations. However, additional on-board medical equipment varies with different airlines depending on their assessment of the risks and economics involved, as shown by a German study. ${ }^{(12)}$ The United States (US) FAA Policy AC121-33B states that all aircrafts with a maximum payload capacity of more than 7,500 pounds with at least one flight attendant are required to be equipped with automated external defibrillators (AEDs). ${ }^{(13)}$ Currently, no other aviation authority has a similar mandate, and hence, not every airline chooses to equip their aircraft with AEDs, depending on their risk-benefit assessments. Locally, Singapore Airlines equipped all their aircrafts with AEDs in 1997. ${ }^{(14)}$

At times, the responding doctor may be fortunate enough to encounter multiple medical professionals on board who also volunteer their services, resulting in a small medical team working together on the IME. In such cases, it is best to allow the most experienced person, or the person with the most appropriate clinical knowledge, to take the lead. The cabin crew can always be called upon to assist, as they would be familiar with the equipment and are usually trained in advanced first aid as well as cardiopulmonary resuscitation and the use of an AED, should it be carried by the airline.
Table I. AsMA, IAASM and IATA recommendations on contents of aircraft kits.

\begin{tabular}{|c|c|}
\hline Kit type & Recommended contents \\
\hline First aid kit & $\begin{array}{l}\text { - Antiseptic swabs (10/pack) } \\
\text { - Bandage adhesive strips } \\
\text { - Bandage, gauze, } 7.5 \mathrm{~cm} \times 4.5 \mathrm{~cm} \\
\text { - Triangular bandage } 100 \mathrm{~cm} \text {, folded, and } \\
\text { safety pins } \\
\text { - Dressing, burns, } 10 \mathrm{~cm} \times 10 \mathrm{~cm} \\
\text { - Sterile dressing, compress, approximately } \\
7.5 \mathrm{~cm} \times 12 \mathrm{~cm} \\
\text { - Sterile dressing, gauze, approximately } \\
10.4 \mathrm{~cm} \times 10.4 \mathrm{~cm} \\
\text { - Adhesive tape, } 2.5 \text {-cm standard roll } \\
\text { - Skin closure strips } \\
\text { - Hand cleanser or cleaning towelettes } \\
\text { - Pad with shield or tape for eye } \\
\text { - Scissors, } 10 \mathrm{~cm} \text { (if permitted by } \\
\text { regulations) } \\
\text { - Adhesive tape, surgical, } 1.2 \mathrm{~cm} \times 4.6 \mathrm{~cm} \\
\text { - Tweezers, splinter } \\
\text { - Disposable gloves (several pairs) } \\
\text { - Thermometer (non-mercury) } \\
\text { - Resuscitation mask with one-way valve } \\
\text { - First-aid manual } \\
\text { - Incident record form }\end{array}$ \\
\hline $\begin{array}{l}\text { Emergency } \\
\text { medical kit }\end{array}$ & $\begin{array}{l}\text { - Sphygmomanometer } \\
\text { (electronic preferred) } \\
\text { - Stethoscope } \\
\text { - Supraglottic airway } \\
\text { - Syringes (appropriate range of sizes) } \\
\text { - Needles (appropriate range of sizes) } \\
\text { - Intravenous catheters } \\
\text { (appropriate range of sizes) } \\
\text { - System for delivering intravenous fluids } \\
\text { - Antiseptic wipes } \\
\text { - Venous tourniquet } \\
\text { - Sharps disposal box } \\
\text { - Gloves (disposable) } \\
\text { - Urinary catheter with sterile lubricating } \\
\text { gel } \\
\text { - Sponge gauze } \\
\text { - Tape adhesive } \\
\text { - Surgical mask } \\
\text { - Emergency tracheal catheter (or } \\
\text { large-gauge intravenous cannula) } \\
\text { - Umbilical cord clamp } \\
\text { - Thermometer (non-mercury) } \\
\text { - Flashlight and batteries } \\
\text { - Bag-valve mask } \\
\text { - Basic life support cards }\end{array}$ \\
\hline $\begin{array}{l}\text { Emergency medical } \\
\text { kit medication list }\end{array}$ & $\begin{array}{l}\text { - Epinephrine 1:1,000 (auto-injectors are } \\
\text { easier to use, including in paediatric } \\
\text { dosage) } \\
\text { - Epinephrine 1:10,000 } \\
\text { - Antihistamine injectable and oral } \\
\text { (recommended to also add paediatric } \\
\text { formulation) } \\
\text { - Antipsychotic drug (e.g. haloperidol) }\end{array}$ \\
\hline
\end{tabular}

(Contd...) 
Table I. (Contd...)

\begin{tabular}{|c|c|}
\hline Kit type & Recommended contents \\
\hline $\begin{array}{l}\text { Emergency medical } \\
\text { kit medication list }\end{array}$ & $\begin{array}{l}\text { - Dextrose, } 50 \% \text { injectable, } \\
50 \text { mL (single-dose ampoule or equivalent) } \\
\text { - Nitroglycerin tablets or spray } \\
\text { - Mild to moderate analgesic/antithermic } \\
\text { (including paediatric formulation) } \\
\text { - Anticonvulsant injection or oral } \\
\text { - Antiemetic injection or oral } \\
\text { - Bronchial dilator inhaler with spacer } \\
\text { - Atropine injection } \\
\text { - Adrenocortical steroid injection or similar } \\
\text { oral absorption equivalent } \\
\text { - Diuretic injection } \\
\text { - Sodium chloride } 0.9 \% \text { ( } 1,000 \text { mL } \\
\text { recommended) } \\
\text { - Acetylsalicylic acid (aspirin) for oral use } \\
\text { - Oral beta blocker } \\
\text { - Anti-diarrhoeals } \\
\text { - Opioid antagonist }\end{array}$ \\
\hline $\begin{array}{l}\text { Universal } \\
\text { precaution kit }\end{array}$ & $\begin{array}{l}\text { - Dry powder that can convert small liquid } \\
\text { spill into a granulated gel } \\
\text { - Germicidal disinfectant for surface } \\
\text { cleaning } \\
\text { - Skin wipes } \\
\text { - Face/eye mask (separate or combined) } \\
\text { - Gloves (disposable) } \\
\text { - Impermeable full-length long sleeved } \\
\text { gown that fastens at the back } \\
\text { - Large absorbent towel } \\
\text { - Pick-up scoop with scraper } \\
\text { - Biohazard disposal waste bag } \\
\text { - Instructions }\end{array}$ \\
\hline
\end{tabular}

AsMA: Aerospace Medical Association; IAASM: International Academy of Aviation and Space Medicine; IATA: International Air Transport Association

Some airlines contract with third-party ground-based medical support companies whose medical staff can provide recommendations in IMEs. These medical experts are able to offer advice to the responding physician or healthcare professional on the aircraft, and in some cases, are also able to call upon the appropriate specialist to confer with. While aviation telemedicine has been in existence since the late 1980s (MedAire, the world's largest provider of telemedicine services for commercial and general aviation, fielded its first telemedicine service via voice consultation in 1987), the increasing bandwidth and reliability of aircraft-to-ground communications has allowed the development of telemedicine via video calls as well as the transmission of investigations such as electrocardiograms. Such services can include specialised equipment on board that is able to transmit data back to specialists on the ground for assessment.

\section{Recommending aircraft diversion}

Diverting the aircraft (i.e. requesting that the aircraft land at a nearer alternative destination) may be the last resort in certain IMEs. While the responding doctor on board the aircraft may determine that the patient needs access to a medical facility immediately, and therefore request that the aircraft be landed at the nearest airport without delay, the final decision on whether to divert the aircraft always rests with the aircraft captain. A decision to divert a large airliner carrying nearly 300 passengers can cost between USD 15,000 and USD 900,000.(7) More importantly, the captain has to consider operational factors, such as whether the nearest airport is compatible with the aircraft, the chosen location has the ability to house the passengers, and there are appropriate medical facilities for managing the IME condition. Operationally, it may also take some time (30 minutes or even more) for the aircraft to descend from cruising altitude to landing. Therefore, the nearest airport may not be the most appropriate landing location for many reasons. In a study, aircraft diversions occurred in only 875 (7.3\%) out of 11,920 cases of IMEs. The medical conditions that most frequently resulted in diversions were cardiac arrest, cardiac symptoms, obstetric emergencies and stroke. ${ }^{(2)}$

\section{WHAT IS THE MEDICOLEGAL LIABILITY?}

The US Aviation Medical Assistance Act provides limited protection to doctors and other medical professionals who volunteer their services in an IME for flights in the US; however, medical liability for flights outside of the US is unclear. Other than Good Samaritan protections, some countries may have laws that require doctors to respond in an emergency, for example in Europe and Australia. Conversely, in the US, Canada, England and Singapore, there is no legal duty for a doctor to volunteer their services during an IME, ${ }^{(4,15)}$ although it can be argued that doctors have a moral obligation to do so. Reassuringly, there have been few instances of doctors being named as a defendant after rendering assistance during an IME, even though airlines have been sued. ${ }^{(16)}$

Even so, it is still the duty of a doctor who volunteers assistance in an IME to provide care that is reasonably expected of a person with his/her skills and experience. A doctor who is grossly negligent when treating a patient will not be able to escape liability, even in the setting of an IME. Doctors who respond to an IME are recommended to document their assessment and treatments administered using the medical forms available, or even on any blank sheet of paper.

Subsequent to assisting in the IME, some airlines may offer a small token of appreciation to the responding healthcare professional. One should be aware that any reward exceeding that of a token may give the impression of a charge or fee. Such a situation changes it to a fee-for-service scenario. This would negate the provisions of any Good Samaritan protection and can expose the doctor to potential litigation if the service provided does not meet a perceived expected standard. (17) For this reason, many doctors would refuse any token of appreciation that appears excessive in order to avoid even the impression of a change in the doctor-patient relationship in the IME. Needless to say, any attempt by the doctor to charge for the services rendered would 
certainly nullify the Good Samaritan protection accorded and also change the expectations of the standard of care provided. ${ }^{(17)}$

\section{WHAT OTHER CONSIDERATIONS ARE THERE IN MANAGING AN IME?}

Although doctors desire to help patients and save lives, our first objective is to do no harm. It is thus of utmost importance that prior to raising your hand to identify yourself as a medical practitioner and volunteering your expertise in an IME, you should first ensure that you are sober enough to perform as a medical provider. Check if you have taken any mild sedatives or antihistamines or in-flight alcoholic beverages that might impair your clinical judgement. As doctors, we should ensure that we are as ready as possible to handle an IME, armed with at least basic knowledge of the unique nature of the aircraft cabin environment, the possible types of medical conditions that may be encountered, and the options that are available.

\section{TAKE HOME MESSAGES}

1. IMEs are becoming more common with increasing passenger numbers, and doctors who are on board are likely to be called upon to respond.

2. The aircraft cabin environment is pressurised to an altitude of only 6,000-8,000 feet, with an atmospheric pressure of $609 \mathrm{mmHg}$ and $564 \mathrm{mmHg}$, respectively.

3. The main effects are a lower partial pressure of oxygen (equivalent to breathing $15.1 \%$ oxygen and having an oxygen saturation of 90\%-93\%), gas expansion (by 30\%) in gas-containing cavities, and extremely dry air $(0 \%-10 \%$ relative humidity).

4. Cardiorespiratory decompensation, barotrauma, dehydration and exacerbation of asthma may occur as a result.

5. Passengers who have recently gone scuba diving are recommended not to fly for at least 24 hours.

6. Some airlines contract with third-party ground-based medical providers, whose staff may provide advice and recommendations in an IME.

7. A doctor volunteering to assist in an IME is generally covered by Good Samaritan protection. However, the physician is still required to provide care that is reasonably expected of a doctor with his/her skill and experience.

8. Following an IME event, a reasonable token of appreciation may be offered and accepted by the doctor. However, care must be taken that this token is not deemed excessive and should not be requested by the responding doctor.
After responding to the call for a doctor, you were asked to assess a fit and tanned young woman who complained of severe pain in multiple joints, which had started abruptly. You astutely uncovered that she had been diving yesterday and had not rested for a day before flying as recommended. Assessing that these bends were only in the joints and it was approximately an hour to your destination, you prescribed a strong analgesic and monitored her until arrival, upon which she was received by the ground medical team via the air bridge.

\section{REFERENCES}

1. International Air Transport Association (IATA). Deep losses continue into 2021. In: Press Release No: 95. Available at: https://www.iata.org/en/pressroom/ pr/2020-11-24-01. Accessed February 23, 2021.

2. Peterson DC, Martin-Gill C, Guyette FX, et al. Outcomes of medical emergencies on commercial airline flights. N Eng J Med 2013; 368:2075-83.

3. Martin-Gill C, Doyle TJ, Yealy DM. In-flight medical emergencies: a review. JAMA 2018; 320:2580-90.

4. Muhm JM, Rock PB, McMullin DL, et al. Effect of aircraft cabin altitude on passenger discomfort. N Eng J Med 2007; 357:18-27.

5. Humphreys S, Deyermond R, Bali I, Stevenson M, Fee JP. The effect of high altitude commercial air travel on oxygen saturation. Anaesthesia 2005; 60:458-60.

6. Tiemensma M, Buys P, Wadee SA. Sudden death on an aeroplane. S Afr Med J 2010; 100:148-9.

7. Ruskin KJ, Hernandez KA, Barash PG. Management of in-flight medical emergencies. Anesthesiology 2008; 108:749-55.

8. International Air Transport Association (IATA). Cabin Air Quality. Available at: https://www.iata.org/en/youandiata/travelers/health/cabin-air/. Accessed February 23, 2021.

9. Federal Aviation Administration. Altitude Induced Decompression Sickness. Available at: https://www.faa.gov/pilots/safety/pilotsafetybrochures/media/DCS. pdf. Accessed February 23, 2021.

10. International Civil Aviation Organisation (ICAO). Annex 6 - Operation of aircraft 2018, Chapter 6.

11. Aerospace Medical Association Air Transport Medicine Committee. Guidance document. Available at: http://www.asma.org/asma/media/AsMA/TravelPublications/FAA-med-kit-Guidance-Document-June-2019.pdf. Accessed February 23, 2021.

12. Hinkelbein J, Neuhaus C, Wetsch WA, et al. Emergency medical equipment on board German airliners. J Travel Med 2014; 21:318-23.

13. Federal Aviation Administration. Policy AC121-33B - emergency medical equipment. Available at: https://www.faa.gov/documentLibrary/media/ Advisory_Circular/AC121-33B.pdf. Accessed February 23, 2021.

14. Charles RA. Cardiac arrest in the skies. Singapore Med J 2011; 52:582-5.

15. Ho SF, Thirumoorthy T, Ng BB. What to do during inflight medical emergencies? Practice pointers from a medical ethicist and an aviation medicine specialist. Singapore Med J 2017; 58:14-7.

16. Aerospace Medical Association. Medical emergencies: managing in-flight medical events (guidance material for health professionals). In: Medical publications for airline travel. Available at: www.asma.org/publications/medicalpublications-for-airline-travel/managing-in-flight-medical-events. Accessed February 23, 2021

17. Shepherd B, Macpherson D, Edwards CM. In-flight emergencies: playing the Good Samaritan. J R Soc Med 2006; 99:628-31. 


\section{SINGAPORE MEDICAL COUNCIL CATEGORY 3B CME PROGRAMME} (Code SMJ 202105B)

1. In-flight medical emergencies (IMEs) take place in about one out of 604 flights.

2. Most IMEs are managed by nurses.

3. The atmosphere in an aircraft cabin is the same as what we experience at sea level.

4. The air in an aircraft cabin has a lower partial pressure of oxygen, which results in passengers having an oxygen saturation of $90 \%-93 \%$.

5. Based on Boyle's law, the volume of gas in an air-containing cavity will expand by $30 \%$ at a cabin altitude of 8,000 feet.

6. Only the sinuses and middle ears are affected by gas volume changes in the air

7. The relative humidity of the air in an aircraft cabin is usually between $0 \%$ and $10 \%$.

8. It is perfectly safe to complete the last scuba dive on a holiday and board an airliner on the same day to fly home.

9. The most common IME is a passenger having a syncopal episode.

10. Obstetric emergencies are one of the most common IMEs and require the attention of a doctor on board.

11. If one needs to lie a patient down flat to perform a procedure, the galley is a good location.

12. All aircraft that carry passengers must have a first-aid kit and a medical kit on board.

13. The contents of medical kits are standardised across all international airlines and are dictated by the International Civil Aviation Organization.

14. Not all airlines carry automated external defibrillators (AEDs) on board their aircraft.

15. The cabin crew can be called upon to assist the doctor in an IME, as they are usually trained in advanced first aid, cardiopulmonary resuscitation and the use of an AED, should it be carried by the airline.

16. The responding doctor can recommend that the aircraft be diverted and landed immediately, but the final decision for diversion rests with the aircraft captain.

17. According to studies, aircraft were diverted in only $7.3 \%$ of IMEs.

18. In Singapore, there is no legal duty for doctors to volunteer their services during an IME.

19. In an IME, as long as a doctor volunteers, he will be protected by Good Samaritan provisions, even if he makes a mistake that is deemed negligent.

20. After responding to an IME, it is reasonable for the doctor to charge the patient, as he has provided a service and will continue to be protected by Good Samaritan provisions.

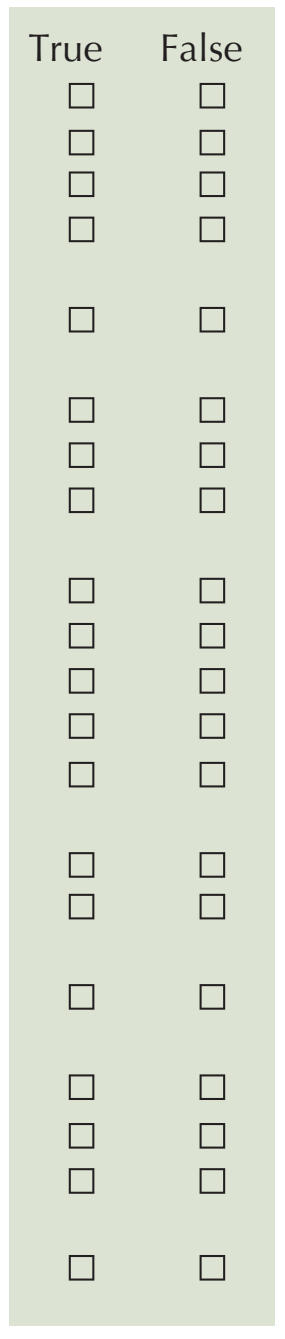

\section{Doctor's particulars:}

Name in full:

MCR no:

Specialty:

Email:

\section{SUBMISSION INSTRUCTIONS:}

Visit the SMJ website: http://www.smj.org.sg/current-issue and select the appropriate quiz. You will be redirected to the SMA login page.

For SMA member: (1) Log in with your username and password (if you do not know your password, please click on 'Forgot your password?'). (2) Select your answers for each quiz and click 'Submit'.

For non-SMA member: (1) Create an SMJ CME account or log in with your SMJ CME username and password (for returning users). (2) Make payment of SGD 21.40 (inclusive of $7 \%$ GST) via PayPal to access this month's quizzes. (3) Select your answers for each quiz and click 'Submit'.

RESULTS:

(1) Answers will be published online in the SMJ July 2021 issue. (2) The MCR numbers of successful candidates will be posted online at the SMJ website by 21 July 2021 . (3) Passing mark is $60 \%$. No mark will be deducted for incorrect answers. (4) The SMJ editorial office will submit the list of successful candidates to the Singapore Medical Council. (5) One CME point is awarded for successful candidates. (6) SMC credits CME points according to the month of publication of the CME article (i.e. points awarded for a quiz published in the May 2021 issue will be credited for the month of May 2021, even if the deadline is in July 2021).

Deadline for submission (May 2021 SMJ 3B CME programme): 12 noon, 14 July 2021. 